\title{
Anniversary Meeting of the Royal Society
}

GIR WILLIAM BRAGG delivered his presidential $S$ address to the Royal Society on November 30 , opening with the customary record of the losses by death of the Society during the past year. These have been unusually heavy, for they have included the Society's patron, H.M. King George V, two foreign members and no less than twenty-one fellows. Reference was made to recent gifts for research to the Universities of Oxford and Cambridge, and to the fact that the Society has undertaken a principal share in the administration of $£ 200,000$ bequeathed by the late Mr. H. B. Gordon Warren, the interest of which is to be applied to the encouragement of research in metallurgy, engineering, physics and chemistry. The capital value of the funds administered by the Society, including the Warren bequest and also the bequest of about $£ 40,000$ by the late Sir Joseph Petavel, is now approximately a million sterling. Surveying some developments of the past few years in the light of the research which has made them possible, Sir William said: "From this point of view the suggestion sometimes made that scientific workers might take a holiday looks more ridiculous than ever. No nation could afford such an intellectual disarmament in the face of the world; nor could the world itself in face of the evils that are to be overcome." There is the danger, however, that research funds may inadvertently lead a man into a blind alley so far as useful occupation is concerned; it should be the business of bodies administering such trusts to see that the highly qualified men they utilize are not wasted when their active research has ended. The address concluded with a discussion of recent developments in the field of the X-ray analysis of crystalline structure (see p. 953).

Sir William Bragg then presented the medals for 1935 ; extracts from his remarks are printed below.

\section{Presentation of Medals}

\section{Copley Medal: Sir Arthur Evans, F.R.S.}

Sir Arthur Evans is awarded the Copley Medal. $\mathrm{He}$ is the leading British authority in classical archæological studies: from his father he inherited a predilection for numismatics, a subject to which, in his earlier years, he made contributions of outstanding importance. His researches in Crete from 1893 onwards resulted in the discovery of the remains of a civilization which he named Minoan after the sea-king, Minos. He traced the development of the Minoan civilization from approximately 3200 to 1400 B.c., from the late Neolithic through the Bronze Age. His Cretan work, published in six volumes, "The Palace of Minos", has revolutionized our knowledge of the ancient history of the Near East.

\section{Rumford Medal: Prof. E. G. Coker, F.R.S.}

The Rumford Medal is awarded to Prof. Ernest George Coker, who has devoted a lifetime to the investigation of stresses in solids by means of polarized light. The original effect was discovered by Brewster in 1815, and Brewster himself suggested that the effect might be used for the direct explora- tion of stress. But although many physicists since Brewster's time investigated the effect, no one, until Coker came, developed a practical method enabling stresses in a model to be actually traced. Coker not only applied to such researches a material, celluloid, not hitherto employed, and capable of being cut to any shape, but he was also the first to devise a reliable instrument (the lateral extenso. meter) for measuring at any point the sum of the principal stresses, which is not directly given by the optical results. In many other ways, he made very important improvements in methods of observation, and he has, in fact, created a new technique and given the engineer a new instrument of discovery. His work is only now beginning to be recognized and taken up by the engineer.

Coker's first paper on this subject dates from 1910 ; since then he has published, either alone or with pupils and colleagues, some fifty or sixty papers, in which he has applied the method to almost every important engineering problem which can be approximated to on two-dimensional lines. In the course of his work, not only has he cleared up a vast number of problems and difficulties, but he has also rendered a great service to applied mathematics, by demon. strating to the engineer the substantial accuracy of the results of the mathematical theory of elasticity.

Coker's work fulfils admirably the condition laid down for the Rumford Medal which says that the discoveries for which it is awarded should be such as "tend most to promote the good of mankind". The results obtained by photo-elasticity in such subjects as the stability of dams and the strength of aeroplane frameworks will certainly be the means of saving many lives. Moreover, Coker has created a world-wide school: to his inspiration is largely due the modern development of photo-elastic laboratories in Japan, the United States, Belgium, Switzerland and Russia.

A Royal Medal: Prof. R. H. Fowler, O.B.E., F.R.S.

A Royal Medal is awarded to Prof. Ralph Howard Fowler. His general theory of statistical mechanics, his later applications of it to the equilibrium of mixed crystals and to a theory of semi-conductors, are of outstanding importance. His paper on dense stellar matter contains the first working out of the properties of a degenerate electron gas, and those on the internal conversion of $\gamma$-rays and on thermionic emission and stray field emission of electrons from metals were fundamental. His work on the theory of the photo-electric effect, especially as a function of temperature, led to a rational means of analysing emission frequency curves, which enables one to determine the true threshold frequencies. His work on the quantum theory of energy exchange between gases and solids broke new ground. Further, he has made notable contributions to the theory of the photo-electric current in semi-conductors, and has made notable contributions in recent years by his adaptation of wave mechanics, as it has been developed, to the solution of problems actually under investigation by groups of experimentalists working in close association with him. 
A Royal Medal: Prof. E. S. Goodrich, F.R.S.

A Royal Medal is awarded to Prof. Edwin Stephen Goodrich. $\mathrm{He}$ is distinguished for his long series of researches on the comparative anatomy, embryology and palæontology of invertebrates and vertebrates, which have thrown light on some of the most fundamental problems of animal morphology. His work on the excretory organs of annelids and of $A m p h i o x u s$ resulted in a new conception of the nephridia and their relation to the cœlom and cœlomoducts. His memoirs on scales of fishes and on the median and paired fins threw fresh light on the classification and phylogeny of fishes and on the evolution of the vertebrate skeleton. His contributions to our knowledge of the segmentation of the vertebrate head are recognized as of the first importance. His volume on cyclostomes and fishes in Ray Lankester's "Treatise on Zoology" and his more recent book, "Studies on the Structure and Development of Vertebrates", are masterly and original contributions to the subject of comparative anatomy. In the opinion of many he is the outstanding morphologist of our time.

\section{Davy Medal: Prof. W. A. Bone, F.R.S.}

The Davy Medal is awarded to Prof. William Arthur Bone, who has had a wide and varied experience in the main branches of chemical science. His early work on the alkyl substituted succinic acids and allied substances, which furnished a valuable chapter in synthetic organic chemistry, was speedily followed by more fundamental researches on the thermal decomposition of hydrocarbons and their oxidation products and by quantitative studies of hydrocarbon combustion. The evidence collected during these prolonged and systematic investigations, devised to include a great variety of experimental conditions of slow combustion and detonation, was overwhelmingly in favour of the hydroxylation theory of the combustion of hydrocarbons. His study of the direct union of carbon and hydrogen led to a synthesis of methane from its elements.

The closely related problem of flame movements in mixtures of burning or exploding gas has been submitted by him to exhaustive examination with improved methods, which made it possible to observe for the first time some striking characteristics of this phenomenon.

On the subject of catalysis, Prof. Bone's contributions are of especial interest and importance. Thus he has recently demonstrated by a variety of convincing experiments that carbonic oxide and oxygen will unite in the gaseous phase in the absence of moisture.

In collaboration with many colleagues and students, Bone has investigated the difficult problem of the chemistry of coal and has applied new physical and chemical methods of identifying the constituents of this complex material. The benzenoid constitution of coals of widely different geological ages and maturity was demonstrated by oxidation experiments which furnished a complete series of the polycarboxylic acids of benzene. In this field of chemical research, Bone will always be regarded as a pioneer.

Darwin Medal: Dr. E. J. Allen, F.R.S.

The Darwin Medal is awarded to Dr. Edgar James Allen, who for the past forty-two years has been director of the Laboratory of the Marine Biological Association at Plymouth.
Allen has made many notable additions to our knowledge of marine biology, dealing with such diverse subjects as the nervous system of the lobster, faunistic studies of estuarine and other areas, systematic work on the Polychæta, the genetics of Gammarus, and contributions to fishery science. $\mathrm{He}$ initiated exact work on the association of bottom faunas with the nature of the deposits and has published valuable papers on the artificial culture of phytoplankton, in which he was one of the earliest to obtain successful results. Many years ago he followed the chain of events leading from sunshine and inorganic constituents of sea-water, through phytoplankton and zooplankton to food fishes, making some of the first contributions to a subject which has since shown striking developments.

When the international fishery investigations began, Allen undertook the English share of the work, which was then based on laboratories at Plymouth and Lowestoft : after the Great War the Lowestoft laboratory branched off and became the Government centre for economic fisheries investigations. He has been closely associated with the International Council for the Exploration of the Sea from its earliest beginnings. The organization of the work on water pollution, carried out by the River Tees Survey Committee, owes much to his initiative, and he is a member of the Committee dealing with similar problems in the River Mersey.

Much of Allen's work has been directed to the study of evolution. The Hooker lecture, which he delivered to the Linnean Society in 1929, deals with the origin of adaptations, and his presidential address to Section D (Zoology) of the British Association in 1922 is again concerned with the evolution of life in the sea.

Throughout his long term of office at Plymouth, Allen has been the inspiration of the workers at the Laboratory, and the success of his labours is shown by the high quality of the research which has been carried out under his direction.

\section{Hughes Medal: Dr. W. Schottky}

The Hughes Medal is awarded to Dr. Walter Schottky of the Central Laboratory of Siemens and Halske, Berlin. $\mathrm{He}$ is best known by his contributions to the fundamental theory of thermionic emission. One of his investigations led in 1914 to the formulation of a theory of the effect of an electric field at the surface of a hot conductor upon the emission of electrons; another led to the discovery of the "Schrot" effect, which attributes certain variations in a thermionic discharge to random emission of individual electrons. He also discovered the so-called 'temperature effect' in ordinary conductors of electricity, which he traced to the thermal agitation of the molecules. Further, he made valuable contributions to the theory of space charge in vacuum tubes in the early days of the subject.

Apart from these mathematical contributions to our knowledge of principles, Schottky has added very greatly to engineering progress in wireless telegraphy. In particular, he invented the screening grid valve which has everywhere superseded the triode valve in the high-frequency amplifiers employed in receiving broadcast signals. $\mathrm{He}$ is also the inventor of the method of super-heterodyne reception wherein the currents of intermediate frequency are amplified. These are two of the most important wireless inventions of the past twenty years. 